\title{
Controlled study comparing CAM treatment with occlusion therapy
}

\author{
K. G. NYMAN, GUR SINGH, AGNETA RYDBERG, AND MONICA FORNANDER
}

From the Department of Ophthalmology, Danderyds Sjukhus, Danderyd-Stockholm, and Karolinska Sjukhuset, Stockholm

SUMMARY A controlled study comparing CAM stimulation and occlusion therapies on 2 equally large, randomly allocated groups of 25 amblyopic children aged between 4 and 61/2 years was conducted. The main parameter of comparison was distant visual acuity. No significant difference was found between the 2 methods as regards mean improvement. By both methods $80 \%$ of the cases showed an improvement of at least 2 lines on the Snellen decimal steps chart. No case showed deterioration.

The treatment of amblyopia is centuries old. A systematic description of occlusion therapy was provided by Leclerc ${ }^{1}$ in 1743 , and to this day the method has by and large remained unchanged. Although occlusion often leads to beneficial results, ${ }^{23}$ there are cases where it is unacceptable to the child and frustrating for the parents. When occlusion has failed other methods have been tried. ${ }^{4-7}$ Dazzling or after-image stimulation of the foveola requires active co-operation from the child and therefore is often applied in a very late stage of the visually immature period. The success rate is poor. Penalisation, ${ }^{8}$ another alternative, works best in cases of amblyopia combined with hyperopia and/or nystagmus.

In one of their earlier papers Hubel and Wiesel ${ }^{9}$ showed that there are cell clusters in the visual cortex that only respond to rectangular stimuli with a specific orientation. Thus different clusters respond to different angles of orientation. This forms the basis of the latest addition to the amblyopia therapy arsenal - the CAM stimulator. In 1978 when Banks et al. ${ }^{1011}$ described the method and the instrument, reporting improvement in 38 of 40 cases, the method seemed very promising. This led us to initiate this study in which CAM treatment was compared with occlusion on equally large randomly allocated groups. Since then others ${ }^{1213}$ have reported that CAM is not only as efficient as occlusion but also produces results sooner and therefore should be the treatment of choice.

Correspondence to Karl G. Nyman MD. Department of Ophthalmology, Danderyds Sjukhus, S-182 88. Danderyd, Sweden.

\section{Patients and methods}

The patients were children aged between 4 and $6 \frac{1 / 2}{2}$ years who as part of the general health programme (this involves virtually all children in the age group) had an eye examination at paediatric care centres in northern part of Greater Stockholm between August 1978 and April 1981. Children who showed a difference of at least 2 rows in distant visual acuity between the 2 eyes (as measured by Snellen E chart with decimal steps) provided the weakest eye did not have a visual acuity better than 0.7 were considered having amblyopia. They were referred to our clinic.

A complete orthoptic assessment was undertaken, cycloplegic refraction ( $1 \%$ atropine topically twice a day for 3 days, one drop on the morning of the examination) and the ocular media and fundus were inspected. When necessary (hyperopia $>1$ D, myopia $>0.5 \mathrm{D}$, and astigmatism $>0.5 \mathrm{D})$ full corrective glasses were provided. After these glasses had been worn for 8 weeks the patients were examined again, including visual acuity. Those who were no longer amblyopic as defined above were excluded from the study. The remaining 50 subjects were randomly allocated to occlusion and CAM groups, 25 in each group.

Occlusion therapy. This consisted of either total occlusion with patching over the eye or Einschleich on the glass. Einschleich, also called Bangerter filter, is a semitransparent membrane available in increasing densities to be applied to the front surface of a spectacle lens. ${ }^{7}$ In cases of tropia the best eye was 
occluded for 5 days alternated by the amblyopic eye for 2. With heterophoria or orthophoria, Einschleich corresponding to a visual acuity of 0.2 less than that of the amblyopic eye was worn continuously in front of the best eye.

$C A M$ therapy. We used the CAM vision stimulator marketed by Clement Clark and followed the procedure as described by Banks et al. ${ }^{1011}$ The amblyopic eye-the fellow eye being occluded only during the treatment-was presented plates with black-and-white gratings, starting with those of the highest, contrast and the child was asked to identify the correct orientation. The plate with the least contrast that was correctly identified and the 2 next of higher contrast were used in the CAM stimulator. Stimulation by the 3 plates took approximately 7 minutes. The number of treatments given varied between 5 and 10 .

Improvement. The criterion was that the visual acuity in the treated eye had to improve by at least 2 lines on the Snellen chart. To be awarded a VA value the child had to identify correctly the middle 4 symbols on the Snellen E chart at the first attempt.

\section{Results}

Tables 1-5 present the distribution of certain variables in the CAM and occlusion groups respectively. Table 1 shows that there is no significant difference of distribution between the 2 groups in the degree of strabismus. Table 2 shows the distribution of the type of deviation being either manifest or

Table 1 Distribution of degree of strabismus in the CAM and occlusion groups prior to treatment

\begin{tabular}{lcclcr}
\hline & \multicolumn{2}{l}{$C A M$} & \multicolumn{3}{l}{ Occlusion } \\
\cline { 2 - 3 } \cline { 5 - 5 } & No. & $\%$ & & No. & $\%$ \\
\hline No strabismus & 6 & 24 & 9 & 36 \\
$\leq 5^{\circ}$ & 4 & 16 & 7 & 28 \\
$>5^{\circ}$ & 3 & 12 & 2 & 8 \\
Phoria & 12 & 48 & 7 & 28 \\
Total & 25 & 100 & 25 & 100 \\
\hline
\end{tabular}

Mann-Whitney U test gives $\mathrm{Z}=1 \cdot 52 . \mathrm{p}=0 \cdot 0643$.

Table 2 Distribution of type of deviation (strabismic or heterophoric) prior to treatment

\begin{tabular}{lll}
\hline & \multicolumn{2}{l}{ No. of patients } \\
\cline { 2 - 3 } & CAM & Occlusion \\
\hline Exo & 10 & 7 \\
Eso & 9 & 9 \\
Ortho & 6 & 9 \\
Total & 25 & 25 \\
\hline
\end{tabular}

heterophoric. Table 3 shows the distribution of refractive errors. As can be seen, the 2 groups are very similar. All children had foveolar fixation. Results of the Bagolini striate glasses test are shown

Table 3 Pretreatment distribution of refractive errors

\begin{tabular}{lll}
\hline & \multicolumn{2}{l}{ No. of patients } \\
\cline { 2 - 3 } & CAM & Occlusion \\
\hline Hyperopia-astigmatism & 17 & 17 \\
Hyperopia & 6 & 6 \\
Astigmatism & 1 & 2 \\
Myopia & 1 & 25 \\
Total & 25 & \\
\hline
\end{tabular}

Table 4 Distribution of Bagolini striate glass test in CAM and occlusion groups prior to treatment

\begin{tabular}{lcccrr}
\hline & \multicolumn{2}{c}{$C A M$} & & \multicolumn{2}{l}{ Occlusion } \\
\cline { 2 - 3 } \cline { 5 - 6 } \cline { 5 - 6 } & No. & $\%$ & & No. & $\%$ \\
\hline Positive & 21 & 84 & & 24 & 96 \\
Negative & 4 & 16 & & 1 & 4 \\
Total & 25 & 100 & & 25 & 100 \\
\hline
\end{tabular}

Table 5 Mean and standard deviation for distant visual acuity in CAM and occlusion groups prior to treatment

\begin{tabular}{lll}
\hline & Mean & $S D$ \\
\hline CAM & $0 \cdot 40$ & $0 \cdot 15$ \\
Occlusion & 0.43 & $0 \cdot 16$ \\
\hline
\end{tabular}

Table 6 Improvement in visual acuity in the CAM group after treatment

\begin{tabular}{lcc}
\hline $\begin{array}{l}\text { Improvement in } \\
\text { no. of lines }\end{array}$ & Frequency & $\%$ \\
\hline 2 & 5 & $26 \cdot 3$ \\
3 & 10 & $52 \cdot 6$ \\
4 & 2 & $10 \cdot 5$ \\
5 & 1 & $5 \cdot 3$ \\
6 & 1 & $5 \cdot 3$ \\
Total & 19 & 100 \\
Mean 3.11, SD 1.05 & & \\
\hline
\end{tabular}

Table 7 Improvement in visual acuity in occlusion group after treatment

\begin{tabular}{lcr}
\hline $\begin{array}{l}\text { Improvement in } \\
\text { no. of lines }\end{array}$ & Frequency & $\%$ \\
\hline 2 & 6 & 30 \\
3 & 6 & 30 \\
4 & 6 & 30 \\
5 & 1 & 5 \\
7 & 1 & 5 \\
Total & 20 & 100 \\
Mean 3.30, SD 1.26 & & \\
\hline
\end{tabular}


Table 8 Improvement in visual acuity in CAM and occlusion groups after treatment

\begin{tabular}{llll}
\hline Therapy & Improvement & $\begin{array}{l}\text { Number of } \\
\text { subjects }\end{array}$ \\
\cline { 2 - 3 } & Less than 2 lines & At least 2 lines & \\
\hline CAM & 6 & 19 & 25 \\
Occlusion & 5 & 20 & 25 \\
\hline
\end{tabular}

in Table 4 . As shown by Table 5 , the 2 groups are very similar regarding distant visual acuity before treatment.

Tables 6 and 7 show the improvement in visual acuity in the 2 groups provided it consisted of 2 lines or more on the Snellen E chart. These results are summarised in Table 8 . Fisher's exact probability test gives a $p$ value of $0 \cdot 50$. Six children in the CAM group and 5 in the occlusion group did not improve. No child deteriorated.

\section{Discussion}

The main object of this study was to compare occlusion treatment with CAM stimulation regarding the parameter distant visual acuity. We have not been able to demonstrate any significant difference. By both methods an improvement of at least 2 lines on the Snellen chart was achieved in $80 \%$ of the cases. As regards CAM, it has not been established that gratings are responsible for the visual improvement. Equally good results with grey discs instead of gratings have been reported. ${ }^{14}$ It may be that the combination of occlusion and near work requiring visual concentration and/or eye-hand stimulation is responsible for the improvement. ${ }^{15}$

We subclassified our material according to the type of amblyopia-anisometropic, strabismic, and stimulus deprivation. The anisometropic group was by far the largest (13 CAM and 12 occlusion); thus it did not allow valid conclusions about differences in improvement in the other subgroups. However, as pointed out earlier, the distributions in CAM and occlusion groups were very similar.
A point of practical interest is that a number of parents found it inconvenient to take time off from their work to accompany the child to our clinic for CAM stimulation twice a week. Some even asked for a switch over to occlusion but were persuaded against it until at least 5 sessions were completed. In summary, we consider that CAM is a useful alternative where occlusion cannot be used.

This work was supported by a grant from Carmen and Bertil Regnérs Research Foundation, Stockholm.

\section{References}

1 Leclerc G, Comte de Buffon. Sur la cause de strabism en les yeux louches. 1743. Mem Acad R Sci 1743; 231-48.

2 Machensen G. Kröner B. Postic G. Kelock W. Untersuchen zum Problem der excentrischen Fixation. Doc Ophthalmol 1967: 23: 228-62.

3 Verronneau-Troutman S. Conventional occlusion or pleoptics in the treatment of amblyopia. Am J Ophthalmol 1974; 78: 117-20.

4 Comberg W. Ein Gerät zur übung des Zentralen Sehens bei funktioneller Schwachsichtigkeit. Ber Dtsch Ophthalmol Ges 1936; 51: 441-3.

5 Bangerter A. Behandlung der Amblyopie. Ophthalmologica 1946: 111: 220-1.

6 Cüppers C. Schielen. Klin Monatsbl Augenheilkd (Beih) 1961: 38: $11-68$.

7 Bangerter A. Steidele M. Wann, Was. Amblyopiebehandlung in der Praxis. St Gall: Zender, 1963.

8 Burian $H$, von Noorden GK. Binocular vision and ocular motility. St Louis, Mosby: 1980: 440-1

9 Hubel DH. Wiesel TN. Receptive fields, binocular interaction and functional architecture in the cat's visual cortex. J Phvsiol 1962; 160: $106-54$

10 Banks RV. Campbell FW. Hess R. Watson PG. A new treatment for amblyopia. Br Orthopt J 1978; 35: 1-12.

11 Campbell FW, Hess R, Watson PG, Banks RV. Preliminary results of a physiologically based treatment of amblyopia. $\mathrm{BrJ}$ Ophthalmol 1978; 62: 748-55.

12 Clark JJ. Malmheden A. Williams AE. Dean L. Willshaw HE. Preliminary survey of the CAM Visual Stimulator. Br Orthopt $J$ 1980; 37: 36-7.

13 Sullivan GD. Fallowfield L. A controlled test of the CAM treatment for amblyopia. Br Orthopt J 1980; 37: 47-55.

14 Tytla ME, Labow-Daily LS. Evaluation of the CAM treatment of amblyopia. a controlled study. Invest Ophthalmol 1980; 20: $400-6$.

15 Kieth CG. Howell ER. Mitchell DE. Smith S. Clinical trial of the use of rotating grating patterns in the treatment of amblyopia. $\mathrm{Br}$ J Ophthalmol 1980; 64: 597-606. 